\title{
PENDAMPINGAN PERSIAPAN UJIAN NASIONAL MELALUI UN CORNER UNTUK SISWA PANTI ASUHAN AISYIAH DAU JETIS MALANG
}

\section{ACCOMPANIMENT OF NATIONAL EXAMINATION PREPARATION THROUGH UN'S CORNER FOR STUDENTS OF 'AISYIYAH DAU JETIS MALANG FEMALE ORPHANAGE}

\author{
M Dintarini1a, A H Khusna1 \\ ${ }^{1}$ Program Studi Pendidikan Matematika, Universitas Muhammadiyah Malang, Jl Raya \\ Tlogomas No. 246 Malang \\ a'Korespondensi: Mayang Dintarini; E-mail: mayangdintarini@umm.ac.id \\ (Diterima: 15-07-2019; Ditelaah: 16-08-2019; Disetujui: 22-09-2019)
}

\begin{abstract}
Aisyiyah Dau Jetis Malang Female Orphanage is a charity foundation for caring female orphans and paupers. This orphanage has 24 students. Based on the results of observations and interviews with the orphanage manager, there are four students who are at the junior high school level and 9 students who are at the senior high school level who will take the National Examination in April 2019. Preparation is needed for these students to face the National Examination. So, the activity of this accompaniment are tutoring, and making UN's Corner. The output of this accompaniment activity are UN's Corner, the collection of Mathematics problem, poster of accompaniment activity and analysis of the results of UN assistance.
\end{abstract}

Keywords: Orphanage, national examination, un's corner

ABSTRAK
Panti Asuhan Perempuan 'Aisyiyah Dau Jetis Malang adalah yayasan amal untuk merawat
anak-anak perempuan yang merupakan yatim piatu dan miskin. Panti asuhan ini memiliki
dua puluh empat siswa. Berdasarkan hasil pengamatan dan wawancara dengan kepala panti
asuhan, terdapat empat siswa yang berada di tingkat sekolah menengah pertama dan
sembilan siswa yang berada di tingkat sekolah menengah atas yang akan mengikuti Ujian
Nasional pada bulan April 2019. Persiapan diperlukan untuk para siswa ini menghadapi
Ujian Nasional. Sehingga, kegiatan pendampingan ini berupa tutoring, dan pembuatan UN's
Corner. Luaran dari kegiatan pendampingan ini adalah UN's Corner, kumpulan soal
Matematika, poster kegiatan pendampingan dan analisis hasil pendampingan.
Kata kunci: Panti asuhan, ujian nasional, un's corner.
Dintarini, M., \& Khusna, A. H. (2019). Pendampingan Persiapan Ujian Nasional Melalui Un
Corner Untuk Siswa Panti Asuhan Aisyiah Dau Jetis Malang. Jurnal Qardhul Hasan; Media
Pengabdian kepada Masyarakat, 5(2),95-100.




\section{PENDAHULUAN}

Ujian Nasional (UN) merupakan standar evaluasi yang ditetapkan oleh pemerintah untuk menilai pencapaian standar nasional pendidikan. UN memiliki tujuan untuk mengendalikan mutu pendidikan di Indonesia (Ikhwanudin, 2017).

Hal ini berarti terdapat nilai batas (cut off score) yang menjadi acuan suatu jenjang pendidikan sudah memenuhi standar nasional pendidikan. Nilai batas yang ditetapkan oleh pemerintah semakin meningkat dan menjadi skor minimal yang harus dipenuhi siswa di seluruh Indonesia agar dapat lulus dan melanjutkan ke jenjang pendidikan yang lebih tinggi (BSNP, 2007). Oleh karena itu UN merupakan hal yang penting untuk diperhatikan karena hasil UN dapat menunjukkan ketercapaian kompetensi peserta didik tersebut. Pentingnya UN menjadi hal yang perlu dipersiapkan secara matang oleh peserta didik.

Matematika merupakan salah satu mata pelajaran yang diujikan pada UN. Mata pelajaran membutuhkan kemampuan dalam berpikir kritis, sistematis, logis, dan kreatif. Dalam langkah-langkah dan konsep yang jelas dalam menyelesaikan masalah matematika (C. Voutsina, 2016). Materi yang diujikan adalah bilangan, aljabar, geometri, pengukuran, statistik serta peluang.

Ujian ikut andil dalam meningkatkan kecemasan siswa terhadap matematika. Matematika seringkali dianggap sulit oleh siswa (Liang \& Wood, 2005). Kecemasan siswa akan beratambah beriringan dengan kenaikan tingkatan siswa, evaluasi/ujian, perbandingan sosial. Beberapa pengalaman kegagalan juga menambah kecemasan siswa dalam belajar materi tertentu, khususnya matematika (Santrock, 2007).

Penelitian lain oleh Hill dan Sarason dalam (Hall, 2005), berdasarkan TASC (test anxiety scale children) didapati bahwa 4.000.0005.000 .000 anak sekolah dasar dan siswa Sekolah Menengah memiliki kecemasan yang besar.
Hasil dari FGD yang dilakukan (Nurlaila, 2011) yang dilakukan diperoleh bahwa siswa merasa khawatir, cemas, dan takut gagal. Para siswa merasa takut tidak lulus, gagal, tidak dapat mengerjakan ujian. Perasaan cemas dan khawatir muncul karena standar nilai kelulusan yang meningkat dibandingkan tahun sebelumnya, jumlah mata pelajaran yang lebih banyak, dan tidak yakin dengan kemampuan dimilikinya. Kondisi yang dirasakan saat menghadapi UAN tersebut membuat mereka merasa tertekan dan tidak nyaman sehingga terkadang sulit konsentrasi ketika belajar, sulitmemahami materi, dan sulit untuk mengatur waktu belajar.

Lembaga Kesejahteraan Sosial Anak Putri (LKSAP) 'Aisyiyah Pimpinan Cabang 'Aisyiyah (PCA) Dau kabupaten Malang Jawa Timur merupakan amal usaha pengasuhan anak dan remaja putri yatim, piatu, yatim piatu dan dhuafa. LKSAP ini memiliki 24 anak asuh. Berdasarkan hasil observasi dan wawancara dengan tim LKSAP, terdapat empat siswa yang berada pada jenjang SMP dan 9 orang siswa yang pada jenjang SMA yang akan mengikuti UN pada April 2019. Diperlukan persiapan yang matang bagi 13 siswa tersebut untuk menghadapi UN, khususnya UN mata pelajaran matematika.

Pendampingan dilakukan dengan tujuan untuk mengurangi kecemasan siswa serta untuk meningkatkan hasil UN siswi Lembaga Kesejahteraan Sosial Anak Putri (LKSAP) 'Aisyiyah. Model pendampingan UN yang dilakukan adalah berupa pendampingan intensif UN serta pengadaan perpustakaan mini. Selain menjadi tempat penyedia informasi perpustakaan memiliki fungsi khusus yaitu sebagai tempat belajar secara mandiri (Shaleh, 2014). Pada pengabdian ini UN Corner merupakan perpustakaan mini khusus untuk persiapan UN. UN Corner menjadi tempat bagi siswa di panti asuhan untuk fokus pada UN. UN Corner difasilitasi buku-buku latihan soal UN serta buku saku persiapan UN. Pada UN Corner juga terdapat tulisan-tulisan yang memotivasi serta kalender UN yang berisi target penguasaan materi siswa. Hal ini bertujuan untuk 
mengatur jadwal materi siswa sehingga pada saat UN semua materi diharapkan telah dikuasai oleh siswa. Luaran dari kegiatan pendampingan ini adalah UN's Corner, kumpulan soal Matematika, poster kegiatan pendampingan dan analisis hasil pendampingan.

\section{MATERI DAN METODE}

Metode pelaksaaan dari kegiatan Pendampingan dan Pembimbingan Olimpiade Matematika ini terdiri dari beberapa tahapan kegiatan. Kegiatan tersebut dimulai dari kegiatan persiapan, kegiatan sosialisasi, kegiatan pendampingan penyusunan Handout, Implementasi dan Analisis keterlaksanaan. Adapun uraian dari masing-masing kegiatan adalah sebagai berikut:

\section{Persiapan}

Kegiatan persiapan ini dimulai dengan kegiatan observasi guna mengetahui kondisi yang berkaitan dengan kegiatan pendampingan UN yang dilakukan di Panti Asuhan Aisyiah. Kegiatan persiapan ini juga dilakukan dengan kegiatan wawancara terhadap Kepala Panti Asuhan. Berdasarkan hasil observasi dan wawancara tersebut, didapati hal yang sangat dibutuhkan anakanak Panti Asuhan ini adalah bimbingan belajar untuk mempersiapkan UN. Tim pengabdian melakukan diskusi internal dan mengkaji literatur guna membahas solusi yang dapat digunakan untuk membantu permasalahan yang ada di panti tersebut berkenaan dengan kegiatan pendampingan UN. Diskusi tersebut berlanjut dengan penyusunan jadwal kegiatan yang akan dilakukan selama pendampingan.

\section{Sosialisasi}

Kegiatan yang dilakukan setelah merancang semua kegiatan dan terdapat penanggung jawab untuk masing-masing kegaiatan yaitu kegiatan sosialisasi. Kegiatan sosialisasi tersebut dilakukan di Panti Asuhan Aisyiah dan melibatkan Tim Dosen, mahasiswa Kepala Panti dan siswa. Sosialisasi ini dilakukan untuk memberikan pengarahan pada Kepala Panti berkenaan dengan kegiatan pendampingan UN dan pembuatan UN Corner.

\section{Pembuatan UN Corner}

UN Corner yaitu tempat khusus bagi siswa di panti asuhan untuk fokus pada UN. UN Corner difasilitasi dengan tersedianya bukubuku latihan soal UN serta buku saku persiapan UN. UN Corner ini memiliki desain yang menarik seperti perpustakaan mini sehingga siswa akan tertarik dan termotivasi untuk mempersiapkan UN. Pada UN Corner juga terdapat tulisan-tulisan yang memotivasi serta kalender UN yang berisi target penguasaan materi siswa. Hal ini bertujuan untuk mengatur jadwal materi siswa sehingga pada saat UN semua materi diharapkan telah dikuasai oleh siswa.

\section{Pendampingan Persiapan UN}

Setelah kegaiatan pembuatan UN Corner, dilanjutkan dengan pendampingan untuk persiapan UN. Kegiatan ini berbentuk pelatihan UN, dimana siswa diberikan Handout dan dibimbing untuk dapat mengerjakan sosl-soal UN dengan benar. Pendampingan persiapan UN ini dilakukan kurang lebih selama 8 kali pertemuan. Di akhir pertemuan akan diadakan Try out untuk melihat kesiapan siswa dalam menghadapi UN.

\section{Evaluasi dan Refleksi}

Kegiatan implementasi selalu diikuti tim pengabdian dengan kegiatan evaluasi guna mengatasi kendala yang terjadi. Selain kegiatan evaluasi, kegiatan selanjutnya yang dilakukan oleh tim pengabdian adalah refleksi untuk keterlaksanaan kegiatan.

Refleksi dilakukan setelah semua kegiatan berjalan, mulai dari perencanaan sampai dengan implementasi. Kegiatan refleksi ini dilakukan oleh tim pengabdian beserta dengan guru pendamping olimpiade dengan jalan tanya jawab dan diskusi. Kegiatan ini dilakukan guna mengetahui apa saja yang terjadi pada saat pelaksanaan berlangsung. Refleksi dilakukan selama 1 pertemuan. 
Adapun skema pelaksanaan kegiatan yang dilakukan selama pengabdian ditunjukkan pada gambar berikut.

Gambar 1. Skema Pengabdian

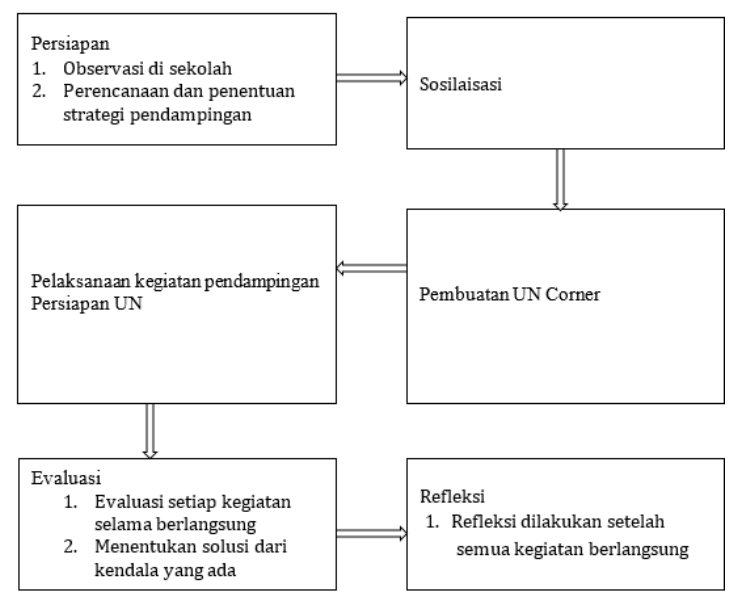

\section{HASIL DAN PEMBAHASAN}

Sesuai dengan metode yang telah dijelaskan kegiatan pendampingan ini dimulai dengan kegiatan persiapan. Kegiatan persiapan terdiri dari dua tahap yaitu tahap observasi dan dilanjutkan dengan perencanaan dan penentuan strategi untuk menyelesaikan masalah yang dihadapi mitra yaitu siswa di Panti Asuhan Aisyiah Dau Jetis Malang. Observasi dilakukan dengan berkunjung ke Panti Asuhan untuk selanjutnya dilakukan wawancara pada pengurus dan siswa Panti Asuhan.

Hasil wawancara dengan pengurus panti diperoleh informasi bahwa siswa di panti asuhan kekurangan dalam pembimbingan dalam belajar materi pelajaran yang ada di sekolah. Terutama siswa kelas XII sebanyak 9 siswa dan kelas IX sebanyak 4 siswa yang akan menghadapi UN. Tidak adanya pendamping ini mengakibatkan siswa kebingungan jika mengalami kesulitan dalam berlatih soal ketika di panti. Selain itu hasil UN siswa panti setiap tahun cenderung sama yaitu memperoleh rata-rata 6. Dari segi aktivitas, siswa di panti dapat memulai. Hasil wawancara dengan siswa diperoleh informasi bahwa siswa masih kekurangan buku soal-soal untuk persiapan UN meskipun di sekolah sudah difasiltasi buku latihan soal. Siswa juga memerlukan adanya pendamping saat di panti ketika siswa mengalami kesulitan.

Selain hasil wawancara peneliti juga melakukan observasi terhadap tempat belajar siswa. Menurut peneliti tempat belajar siswa kurang representatif. Siswa belajar di mushola dengan alas sholat dan papan tulis yang masih menggunakan kapur tulis. Selain itu siswa juga tidak memiliki tempat untuk menaruh buku (rak buku). Dari segi penerangan lampu yang digunakan cenderung redup. Kurangnya fasilitas ini akan mempengaruhi minat belajar siswa (Hanrahan, 1998).

Berdasarkan hasil observasi dan wawancara tersebut pengabdian selanjutnya melakukan perencanaan untuk menentukan strategi penyelesaian masalah yang dihadapi oleh mitra. Dalam melakukan perencanaan peneliti melakukan studi literartur serta diskusi dengan tim terkait solusi yang akan diberikan. Selanjutnya adalah menentukan strategi pemecahan masalah yaitu dengan memberikan fasiitas pada siswa di panti berupa pendampingan persiapan UN melalui UN Corner. Selain itu peneliti juga memfasilitasi adanya tutor untuk membantu siswa saat mengalami kesulitan. Sehingga pada tahap ini peneliti juga menyusun jadwal untuk melakukan kegiatan pendampingan ini.

Adapun kegiatan pendampingan yang dilakukan adalah Pendampingan dilaksanakan sebanyak 16 kali. Masingmasing 8 pertemuan untuk pendampingan siswa SMP dan 8 pertemuan siswa SMA. Pendampingan terdiri dari 7 pertemuan tutoring dan 1 pertemuan try out.

Tahap selanjutnya adalah kegiatan sosialisasi pendampingan persiapan UN kepada siswa dan pengurus panti. Hal ini bertujuan untuk menyesuaikan jadwal kegiatan yang dibuat oleh peneliti dengan jadwal kegiatan yang ada di panti serta pemilihan tempat yang strategis yang akan dijadikan sebagai tempat untuk UN Corner. Tahap ini menghasilkan adanya kesepakatan antara pihak panti dengan pengabdian yaitu 
pihak panti menyetujui kegiatan yang akan dilakukan peneliti.

Berikutnya adalah tahap pembuatan UN Corner. UN Corner yaitu tempat khusus bagi siswa di panti asuhan untuk fokus pada persiapan UN. UN Corner difasilitasi dengan tersedianya buku-buku latihan soal UN serta buku saku persiapan UN. Selain buku latihan soal peneliti juga menyiapkan modul yang berisi uraian materi singkat dan latihan per KD agar siswa lebih memahami materi yang akan diujikan. UN Corner ini memiliki desain yang menarik seperti perpustakaan mini sehingga siswa akan tertarik dan termotivasi untuk mempersiapkan UN.

Gambar 2. UN Corner

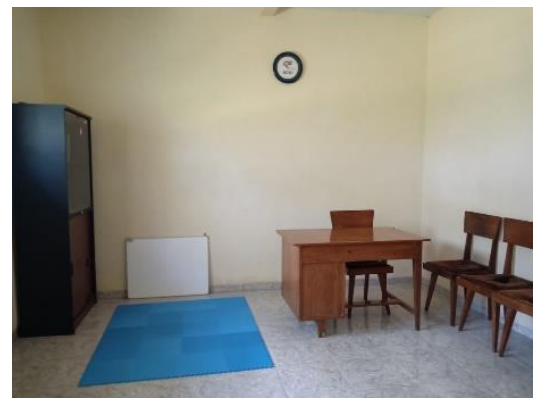

Pada UN Corner juga terdapat tulisantulisan yang memotivasi serta kalender UN yang berisi target penguasaan materi siswa. Hal ini bertujuan untuk mengatur jadwal materi siswa sehingga pada saat UN semua materi diharapkan telah dikuasai oleh siswa.

Selain memfasilitasi siswa panti asuhan dengan UN Corner, peneliti juga memfasilitasi siswa dengan adanya kegiatan pendampingan persiapan UN yang diadakan selama 16 kali pertemuan. Dalam pendampingan ini siswa berlatih soal-soal UN dengan tutor yang telah disediakan. Kegiatan pendampingan ini dilaksanakan setelah sholat isya' sampai pukul 21.00 WIB.

Gambar 2. Kegiatan pendampingan UN.

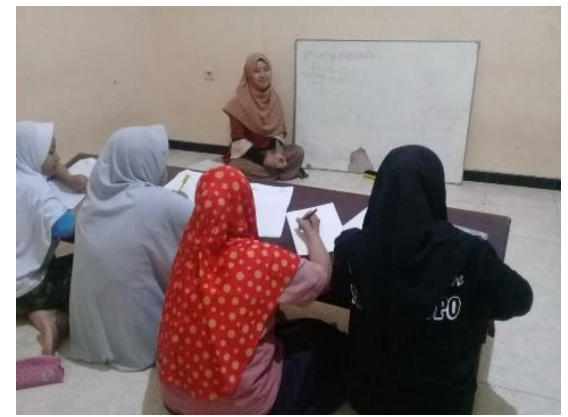

Kegiatan pendampingan UN dilakukan dengan didampingi oleh dua tutor dan menggunakan model pembelajaran berkelompok serta diskusi secara klasikal. Hal ini dipilih karena pembelajaran dengan berdiskusi kooperatif lebih efektif pada hasil belajar siswa (Tarim\&Akdeniz, 2007). Sebelum memulai pendampingan siswa diberikan pretest dengan diberikan soal UN tahun 2018. Hasil pretest menunjukkan bahwa rata-rata siswa memperoleh nilai 5,2. Gambar 3. Siswa Berdiskusi.

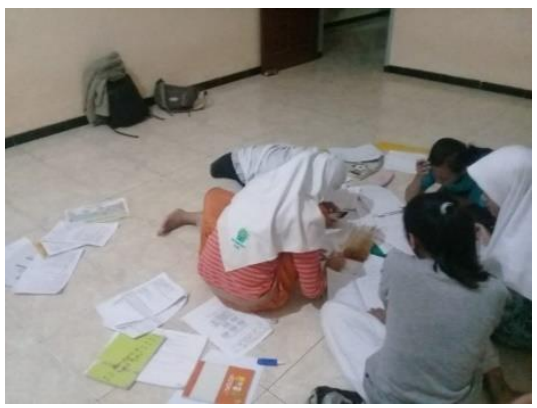

Tahap evaluasi dilakukan setelah siswa menempuh UN. Tahap evaluasi dilakukan dengan membandingkan nilai yang diperoleh siswa pada saat pretest dengan hasil tryout yang diadakan oleh peneliti. Hasilnya adalah nilai rata-rata siswa meningkat dari 5,2 menjadi 6,8. Hal ini berarti pendampingan yang dilakuakn dengan difasilitasi adanya UN Corner dapat meningkatkan hasil belajar siswa. Adapun kekurangan dari kegiatan pendampingan ini adalah kurangnyya frekuensi tatap muka dengan tutor yang hanya 16 kali pertemuan.

\section{KESIMPULAN}

Kegiatan pengabdian yang dilaksanakan berupa pendampingan persiapan UN siswa di Panti Asuhan Aisyiah Dau Jetis Malang. Kegiatan ini dilakukan berdasarkan pada masalah yang ada di panti asuhan yaitu kurangnya fasilitas berupa bahan ajar serta tutor untuk mendampingi siswa di panti asuhan untuk mempersiapkan UN. Permasalahan tersebut diselesikan dengan cara (1) diadakannya UN Corener yaitu tempat khusus bagi siswa di panti asuhan untuk fokus pada persiapan UN dan (2) program pendampingan UN yang dilaksanakan selama 16 kali pertemuan. 
Hasil yang diperoleh dari kegiatan ini adalah rata-rata nilai siswa meningkat dari 5,2 menjadi 6,8. Kekurangan dari program ini adalah kurangnya frkuiensi pendampingan sehingga hasil yang diperoleh kurang maksimal.

\section{DAFTAR PUSTAKA}

BSNP. (2007). Prosedur Operasi Standar Ujian Nasional Sekolah Menengah Pertama. Retrieved from www.bsnp.org

C. Voutsina. (2016). Oral counting sequences: a theoretical discussion and analysis through the lens of representational redescription. Educational Studies in Mathematics, 93(2), 175-193.

Hall, T. S. (2005). Is test anxiety a form specific social phobia. University of Maryland College.

Hanrahan, Mary U. (1998) The effect of learning environment factors on students' motivation and learning. International Journal of Science Education, 20(6), pp. 737-753.

Ikhwanudin, T. (2017). Model Pendampingan Guru Dalam Menghadapi Pelaksanaan Ujian Nasional Matematika Di Sekolah Inklusif. PRISMA, 6(2).

Liang, C. B., \& Wood, E. (2005). Working with Logarithms: Students' Misconceptions and Errors. The Mathematics Educator, 8(2), 53$70 . \quad$ Retrieved from http://repository.nie.edu.sg/jspui/bitstream /10497/69/1/ME-8-2-

53.pdf $\backslash$ nhttp://math.nie.edu.sg/ame/mathe duc/tme/tmeV8_2/Final Chua Wood.pdf

Nurlaila, S. (2011). PELATIHAN EFIKASI DIRI UNTUK MENURUNKAN KECEMASAN PADA, 1(1).

Santrock, J. (2007). Adolescence (8th ed.). New York: University of Texas at Dallas.

Tarim, K., \& Akdeniz, F. (2008). The effects of cooperative learning on Turkish elementary students' mathematics achievement and attitude towards mathematics using TAI and STAD methods. Educational studies in Mathematics, 67(1), 77-91. 